\title{
Studi Fungi Mikoriza Arbuskula di Lahan Pasca Tambang Timah Kabupaten Bangka Tengah
}

\section{Study of Arbuscular Mycorrhizal Fungi in Tin Post- Mining Land of Central Bangka Regency}

\author{
TUTI SURYATI \\ Balai Teknologi Pengolahan Air dan Limbah, Badan Pengkajian dan Penerapan Teknologi \\ Gedung 820 Geostech, Kawasan Puspiptek Serpong, Tangerang Selatan, Provinsi Banten, 15314 \\ tisuryati@yahoo.com
}

\begin{abstract}
The activities of tin mining has altered the fertile land into a critical ecosystem. Efforts to recover such conditions were performed through reclamation or revegetation. Improving good performance of the methods can be done through the use of Arbuscular Mycorrhizal Fungi. The study was aimed to obtain local Arbuscular Mycorrhizal Fungi from tin post-mining land located at Central of Bangka Regency. The obtained micorryzhal will be developed for inoculum source that will be implemented in land remediation of the aforementioned post-mining land. Results of the study demonstrated that the number of mycorrizha spore at rhizosphere areas from 23 soil samples consisted of 3 genuses, namely Glomus sp., Gigaspora sp., And Acaulospora sp. Glomus were found at most sites. The highest number of spores recovered from root of rhizosphere Pennisetum purpureum Schumach that has total of 82 spores $/ 50 \mathrm{~g}$ soi. It consisted of 2 types of Mycorrhizal that is Gigaspora and Glomus were obtained at Nibung. Meanwhile, the highest number of colonization percentage was 52\% that was found in the roots of Cyperus polystachyus Rottb of Kayu Ara tin post-mining land
\end{abstract}

Keywords : Arbuscular micorhiza fungi, tin post-mining land, reclamation, remediation

\begin{abstract}
ABSTRAK
Kegiatan penambangan timah telah merusak lahan subur menjadi lahan yang sangat kritis yang merusak ekosistem di dalamnya. Salah satu upaya yang dilakukan untuk mengembalikan lahan tersebut menjadi lahan produktif adalah melalui reklamasi atau revegetasi. Untuk meningkatkan keberhasilan program tersebut salah satunya dilakukan dengan penggunaan Fungi Mikoriza Arbuskula (FMA). Penelitian ini bertujuan untuk mendapatkan mikoriza lokal dari lahan pasca tambang timah Kabupaten Bangka Tengah yang akan dikembangkan sebagai sumber inokulum untuk kemudian diaplikasikan dalam pemulihan lahan pasca tambang timah di Kabupaten Bangka Tengah. Hasil penelitian menunjukkan bahwa analisis jumlah spora FMA dari 23 sampel tanah di area rizosfir tumbuhan lahan pasca tambang timah ditemukan 3 genus FMA, yakni Glomus sp., Gigaspora sp., dan Acaulospora sp. Glomus ditemukan di sebagian besar lokasi penelitian. Jumlah spora terbanyak ditemukan dari rizosfir akar Pennisetum purpureum Schumach yang berjumlah 82 spora/50 g tanah dengan 2 jenis FMA yakni Gigaspora dan Glomus yang diperoleh dari lokasi lahan pasca tambang Nibung. Persentase kolonisasi terbesar yaitu $52 \%$ ditemukan pada akar Cyperus polystachyus Rottb dari lahan pasca tambang timah Kayu Ara.
\end{abstract}

Kata Kunci : Fungi mikoriza arbuskula, lahan pasca tambang timah, reklamasi, remediasi

\section{PENDAHULUAN}

Kegiatan penambangan timah, baik tambang konvensional maupun inkonvensional memberikan dampak terhadap lingkungan hidup yaitu bertambahnya lahan kritis akibat berkurangnya luas hutan, rusaknya lahan pertanian dan $\operatorname{kebun}^{(1)}$. Secara umum, lahan bekas tambang timah terdiri dari kolong (lahan bekas penambangan yang berbentuk semacam danau kecil dengan kedalaman mencapai 40 $\mathrm{m})$, overburden (timbunan liat hasil galian), dan hamparan taling yang berupa rawa atau lahan kering $^{(2)}$. Tailing merupakan bahan dengan komponen utama berupa fraksi pasir bercampur kerikil, dan sejalan dengan waktu timbunan tailing ini akan membentuk hamparan tailing ${ }^{(3)}$. Tekstur tailing yang terbentuk tersebut umumnya didominasi oleh fraksi berupa pasir dengan proporsi yang sangat tinggi, yakni 88 - 
$96 \%$. Hamparan yang demikian selain tidak memiliki estetika lingkungan yang baik juga tidak memiliki manfaat ekologik. Selain itu fakta menunjukkan bahwa proses pemulihan alami berlangsung sangat lambat bahkan untuk pengamatan hingga 20 tahun. Oleh sebab itu perlu adanya terobosan teknologi lingkungan untuk mengubah hamparan miskin unsur hara dan biota tersebut menjadi bentang lahan dengan keadaan ekosistem yang kondusif dan bermanfaat tidak saja bagi kehidupan biota yang terpulihkan tetapi juga bagi manusia yang berkepentingan dengan ekosistem tersebut.

Salah satu aplikasi bioteknologi dalam upaya pemulihan lahan kritis adalah pemanfaatan Fungi Mikoriza Arbuskula (FMA). FMA merupakan agen hayati yang mampu membantu dalam program rehabilitasi lahan pasca pertambangan dan pembenah lahan kritis. Tanaman yang berasosiasi dengan FMA dapat lebih banyak menyerap unsur hara seperti $\mathrm{P}, \mathrm{K}, \mathrm{Ca}, \mathrm{Mg}, \mathrm{Fe}, \mathrm{Cu}, \mathrm{Na}, \mathrm{S}$, dan $\mathrm{Mn}^{(4)}$. Kemampuan fungi mikoriza tidak hanya terbatas pada peningkatan solubilitas mineral dan memperbaiki absorpsi nutrisi tanaman (terutama fosfat), tetapi juga dapat mengurangi stres karena temperatur dan serangan patogen akar. Dengan cara tersebut maka daya hidup dan pertumbuhan tanaman pada lahan marginal dapat ditingkatkan ${ }^{(5)}$. Faktor lain sebagai faktor kritis dalam revegetasi lahan tambang, dan merupakan salah satu kemampuan mikoriza adalah toleransi akan kekeringan. Peran FMA secara tidak langsung meningkatkan ketahanan terhadap kadar air yang ekstrim. Fungi mikoriza dapat mempengaruhi kadar air tanaman inang ${ }^{(6)}$. Jaringan hifa eksternal dari mikoriza akan memperluas bidang serapan air dan hara. disamping itu ukuran hifa yang lebih halus dari bulu-bulu akar memungkinkan hifa bisa menyusup ke pori-pori tanah yang paling kecil (mikro) sehingga hifa bisa menyerap air pada kondisi kadar air tanah yang sangat rendah ${ }^{(7)}$. Asosiasi ini merupakan mekanisme yang sangat penting untuk mengatasi lingkungan yang kurang menguntungkan seperti lahan bekas tambang.

Penelitian ini bertujuan untuk mengetahui keberadaan dan keragaman fungi mikoriza arbuskula (FMA) di areal pasca penambangan timah Kabupaten Bangka Tengah. FMA lokal yang diperoleh akan dikembangkan sebagai sumber inokulum untuk kemudian diaplikasikan dalam upaya meningkatkan keberhasilan pemulihan lahan pasca tambang timah. Isolasi fungi mikoriza dari lahan bekas tambang dapat dijadikan sebagai sumber inokulum untuk kegiatan revegetasi lahan ${ }^{(8)}$.

\section{BAHAN DAN METODE}

\subsection{Waktu dan Tempat}

Pengambilan sampel tanah dan tanaman dilakukan di tiga lokasi lahan pasca tambang timah Kabupaten Bangka Tengah yaitu lahan pasca tambang timah Nibung (S 02 30' 52,9”, E 106 23' 36,6“), Jongkong (S 02 32' 33'4”, E 106 24' 31,0 “) dan Kayu Ara (S 02 33' 04,2 “, E 106 31 ' 50,9“). Waktu pengambilan sampel dilakukan pada bulan Pebruari tahun 2013. Identifikasi tumbuhan dilakukan di Herbarium Bogoriensis Pusat Penelitian Biologi LIPI Cibinong Bogor. Isolasi, identifikasi dan observasi kolonisasi FMA dilakukan di Laboratorium Bioteknologi Hutan dan Lingkungan, Pusat Penelitian Simberdaya Hayati dan Bioteknologi, IPB Bogor. Analisis kimia fisik tanah dilakukan di Laboratorium Tanah Balai Penelitian Tanah, Badan Penelitian dan Pengembangan Pertanian, Bogor.

\subsection{Bahan dan Alat.}

Bahan yang digunakan dalam penelitian ini adalah sampel tanah dan akar tanaman dari areal lahan pasca tambang timah Kabupaten Bangka Tengah Provinsi Bangka Belitung, larutan glukosa $60 \%, \mathrm{KOH} 10 \%, \mathrm{HCL} 2 \%$, larutan Trypan Blue 0,05\%, melzer's reagent dan Aquades. Alat-alat yang digunakan untuk pengambilan sampel tanah dan akar tanaman adalah cangkul, sekop, kantong plastik, spidol dan kertas label. Sedangkan untuk pengamatan di laboratorium adalah saringan bertingkat 710 $\mu \mathrm{m}, 415 \mu \mathrm{m}$, dan $45 \mu \mathrm{m}$ ), sentrifuse, pipet plastik, pinset spora, mikroskop, kaca preparat, cover glass, petridish, pipet, timbangan analitik, gunting akar, sprayer.

\subsection{Prosedur kerja}

\subsubsection{Kepadatan dan keragaman spora}

Analisis kepadatan dan keragaman spora dilakukan terhadap sampel tanah di lahan pasca penambangan timah pada areal yang dapat mewakili keadaan areal pasca tambang timah secara umum. Pengambilan sampel tanah dari lapangan diambil sebanyak \pm 500 gram untuk setiap sampel. Sampel diambil di area rhizosfer akar tanaman dengan kedalaman $\pm 10-30 \mathrm{~cm}$. Metode analisis kepadatan spora menggunakan teknik Wet Sieving Decanting atau penyaringan basah ${ }^{(9)}$. Prosedur kerjanya yaitu sampel tanah sebanyak 50 gram dicampurkan dengan 400$500 \mathrm{ml}$ air dan diaduk sampai butiran-butiran tanahnya hancur. Selanjutnya disaring dalam satu set saringan dengan ukuran $710 \mu \mathrm{m}$ sampai $45 \mu \mathrm{m}$, secara berurutan dari atas ke 
bawah. Saringan bagian atas disemprot dengan air kran untuk memudahkan bahan saringan lolos. Kemudian saringan paling atas dilepas, dan pada saringan kedua tersisa sejumlah tanah yang tertinggal pada saringan terbawah dipindahkan ke dalam tabung sentrifuse. Kemudian tabung tersebut di sentrifuse dengan teknik sentrifugasi ${ }^{(10) .}$ Hasil saringan tanah dalam tabung sentrifuse ditambahkan glukosa $60 \%$ sampai $2 / 3$ isi tabung. Tabung sentrifuse ditutup rapat dan di sentrifuse dengan kecepatan 2500 rpm selama 5 menit.

Selanjutnya cairan yang bening diambil dan dituangkan kedalam saringan yang berukuran $45 \mu \mathrm{m}$, lalu dicuci dengan air mengalir untuk menghilangkan gulanya. Setelah dicuci, spora yang ada dipindahkan ke dalam cawan petri dan dihitung jumlahnya. Identifkasi spora dilakukan menggunakan metode Schenk dan Perez ${ }^{(11)}$, yaitu melalui pengamatan morfologi spora dan preparat slide spora yang diwarnai dengan pewarnaan melzer's reagent. Setelah dapat dilihat dibawah mikroskop kemudian diidentifikasi genusnya. Pengelompokan spora FMA berdasarkan morfologi spora dan pedoman taksonomi dari Invam ${ }^{(12)}$.

\subsubsection{Pengamatan infeksi akar.}

Infeksi akar diamati dari akar tumbuhan yang hidup di lahan pasca tambang timah yang umumnya didominasi oleh tumbuhan gulma. Sampel akar yang diambil adalah akar serabut dari masing-masing tumbuhan. Untuk dapat melihat infeksi akar tersebut perlu dilakukan pewarnaan akar dengan metode Phillips, JM., dan Hayman, DS., ${ }^{(13)}$, yang dimodifikasi. Tahapan pewarnaan tersebut ialah : sampel akar dari lapangan (akar serabut) dipotong. Akar tersebut kemudian dicuci dengan air mengalir sampai kotoran hilang, kemudian direndam dalam larutan $\mathrm{KOH} 10 \%$, sampai akar berwarna putih atau kuning bening, kemudian akar dibilas dengan air bersih agar larutan $\mathrm{KOH}$ hilang. Setelah itu rendam dalam larutan asam klorida $(\mathrm{HCl}) 2 \%$ selama \pm 24 jam, kemudian bilas dengan air bersih untuk menghilangkan $\mathrm{HCl}$. Terakhir akar direndam dengan larutan staining trypan blue $0,05 \%$ sampai akar berwarna biru. Untuk pengamatan infeksi akar tersebut, dilakukan dengan memotong akar yang telah diwarnai sepanjang $1 \mathrm{~cm}$, kemudian akar ditata di atas kaca preparat dan ditutup dengan cover glass. Jumlah akar tiap preparat sebanyak 10 potong. Infeksi akar dapat dilihat melalui adanya vesikula, arbuskula, hifa maupun spora yang menginfeksi akar.

\subsubsection{Perhitungan infeksi akar.}

Rumus untuk perhitungan infeksi akar sebagai berikut ${ }^{(13)}$ :

Akar terinfeksi $(\%)=$

$\sum$ contoh akar terinfeksi $\quad X \quad 100 \%$ $\sum$ contoh seluruh akar yang diamat

Analisis data untuk identifikasi spora, persentase kolonisasi spora dan kepadatan spora dilakukan secara deskriptif.

\section{HASIL DAN PEMBAHASAN}

Lokasi dan titik sampling tanah dan tanaman di lahan pasca tambang timah dicantumkan pada Gambar 1 dan 2. Sampel tanah dari lahan pasca tambang timah tersebut didominasi oleh pasir dengan KTK yang rendah yaitu lahan pasca tambang Nibung 1,05 $\mathrm{cmol} / \mathrm{kg}$, Kayu Ara $0,89 \mathrm{cmol} / \mathrm{kg}$ dan Jongkong $3,62 \mathrm{cmol} / \mathrm{kg}$. Rasio $\mathrm{C} / \mathrm{N}$ juga rendah yaitu Nibung 9 (C 0,18\% dan N 0,02\%), Kayu Ara 13 (C $0,13 \%$ dan $\mathrm{N} 0.01 \%$ ) dan Jongkong 10 (C $0,6 \%$ dan $\mathrm{N} 0,06 \%$ ). Oleh karena itu tanah tersebut sangat miskin unsur hara dan masuk dalam katagori tanah marginal. Walaupun demikian di lahan tersebut tumbuh beberapa jenis tumbuhan yang dapat beradaptasi dengan lingkungan tersebut, yang umumnya didominasi oleh tumbuhan gulma. Terhadap tumbuhan tersebut dilakukan sampling untuk mengetahui keberadaan Fungi Mikoriza Arbuskula (FMA), yang mungkin berkaitan dengan daya adaptasi tumbuhan tersebut terhadap lingkungan lahan pasca tambang yang sangat marginal.

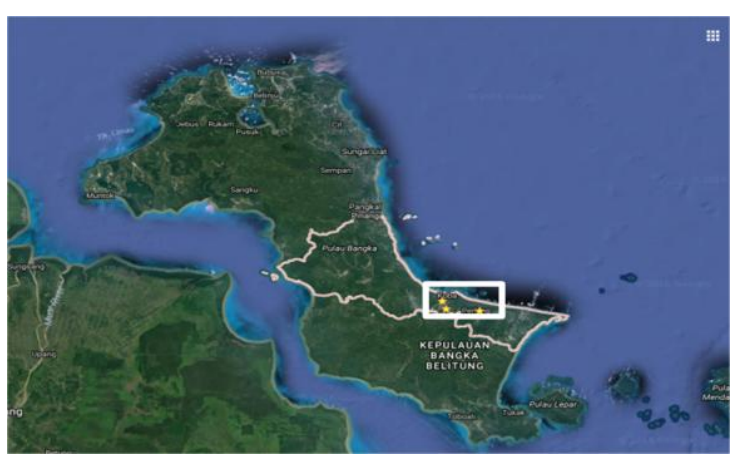

Gambar 1. Lokasi sampling berada di Kabupaten Bangka Tengah, Kepulauan Bangka, Provinsi Bangka Belitung. 


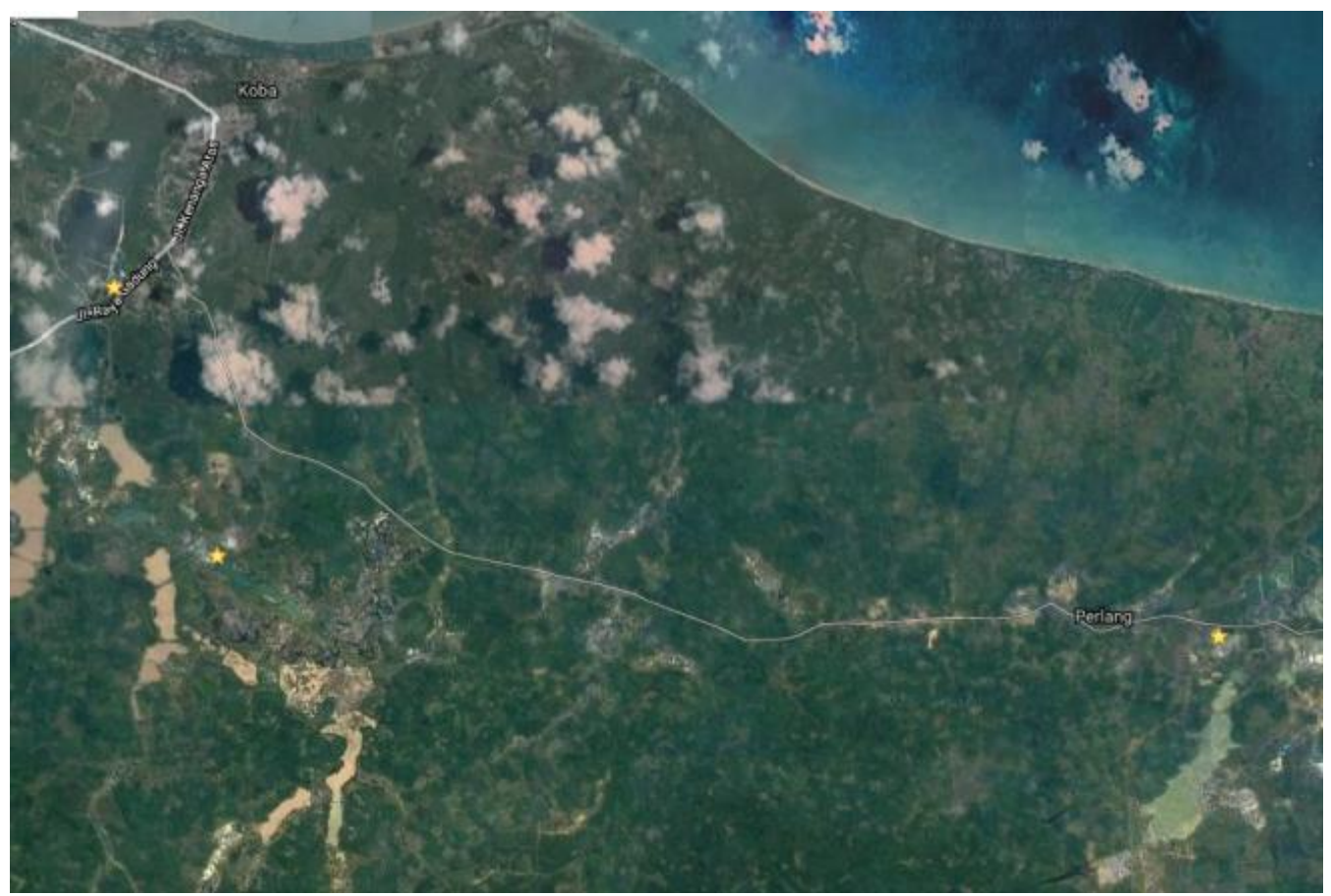

Gambar 2. Titik sampling ditandai dengan bintang warna kuning : Kolong Nibung kiri atas, Kolong Jongkong kiri bawah dan Kolong Kayu Ara sebelah kanan.

Hasil analisis jumlah spora FMA pada tanah di area rizosfir tumbuhan lahan pasca tambang timah tersebut dapat dilihat pada Tabel 1 sampai 3.

Tabel 1. Jenis tanaman, jumlah spora dan genus spora yang ditemukan di lahan pasca tambang timah Nibung Kabupaten Bangka Tengah

\begin{tabular}{lll}
\hline \multicolumn{1}{c}{ Jenis Tanaman } & \multicolumn{1}{c}{$\begin{array}{c}\text { Genus } \\
\text { FMA }\end{array}$} & $\begin{array}{c}\text { Jumlah } \\
\text { Spora/50 } \\
\mathrm{g}\end{array}$ \\
\hline $\begin{array}{l}\text { Fimbrystylis pauciflora } \\
\text { R. Br. }\end{array}$ & Glomus & 40 \\
$\begin{array}{l}\text { Jucciaea linifolia Vahl } \\
\text { Pennisetum }\end{array}$ & $\begin{array}{l}\text { Glomus } \\
\text { Gigaspora }\end{array}$ & 24 \\
$\begin{array}{l}\text { purpureum Schumach } \\
\text { Cynodon dactylon (L.) }\end{array}$ & $\begin{array}{l}\text { Glomus } \\
\text { Gers. }\end{array}$ & Glomus \\
$\begin{array}{l}\text { Eragrotis aatrovirens } \\
\text { (Desf.) Trin. Ex Steud }\end{array}$ & Glomus & 7 \\
$\begin{array}{l}\text { Eleusine indica } \\
\text { Melastoma }\end{array}$ & $\begin{array}{l}\text { Gigaspora } \\
\text { malabathrichum }\end{array}$ & 57 \\
$\begin{array}{l}\text { Xyris complanata R. } \\
\text { Br. } \\
\text { Cyperus polystachyus }\end{array}$ & - & 0 \\
Rottb & - & 0 \\
\hline
\end{tabular}

Tabel 2. Jenis tanaman, jumlah spora dan genus spora yang ditemukan di lahan pasca tambang timah Jongkong Kabupaten Bangka Tengah

\begin{tabular}{lcc}
\hline \multicolumn{1}{c}{ Jenis Tanaman } & $\begin{array}{c}\text { Genus } \\
\text { FMA }\end{array}$ & $\begin{array}{c}\text { Jumlah } \\
\text { Spora/50 g }\end{array}$ \\
\hline $\begin{array}{l}\text { Scleria } \\
\text { purpurascens }\end{array}$ & - & 0 \\
$\begin{array}{l}\text { Steud } \\
\text { Gleichenia linearis }\end{array}$ & Glomus & 2 \\
$\begin{array}{l}\text { (Burm.) C.B.Clarke } \\
\text { Fimbristylis }\end{array}$ & Glomus & 1 \\
dichotoma (L.) Vahl & Axonopus \\
$\begin{array}{l}\text { compressus (Sw) } \\
\begin{array}{l}\text { P. Beauv } \\
\text { Cyperus }\end{array}\end{array}$ & Glomus & 5 \\
polystachyus Rottb & Glomus & 12 \\
$\begin{array}{l}\text { Sporobolus } \\
\text { viriginicus (L.) }\end{array}$ & Glomus & 11 \\
$\begin{array}{l}\text { Kunth } \\
\text { Chromolaena }\end{array}$ & - & 0 \\
odorata \\
$\begin{array}{l}\text { Fuirena umbellata } \\
\text { Rottb }\end{array}$ & - & 0 \\
Scleria levis Rotz & - & 0 \\
\hline
\end{tabular}


Tabel 3. Jenis tanaman, jumlah spora dan genus spora yang ditemukan di lahan pasca tambang timah Kayu Ara Kabupaten Bangka Tengah

\begin{tabular}{lcc}
\hline \multicolumn{1}{c}{ Jenis Tanaman } & $\begin{array}{c}\text { Genus } \\
\text { FMA }\end{array}$ & $\begin{array}{c}\text { Jumlah } \\
\text { Spora/50 g }\end{array}$ \\
\hline Scirpus mucronatus & - & 0 \\
$\begin{array}{l}\text { L. } \\
\text { Ischaemum } \\
\text { aristatum L. }\end{array}$ & $\begin{array}{c}\text { Acaulosp } \\
\text { ora } \\
\text { Glomus }\end{array}$ & 8 \\
$\begin{array}{l}\text { Fuirena umbellata } \\
\text { Rottb }\end{array}$ & $\begin{array}{l}\text { Glomus } \\
\begin{array}{l}\text { Cyperus } \\
\text { polystachyus Rottb }\end{array}\end{array}$ & 8 \\
\hline
\end{tabular}

Di lokasi penelitian tersebut ditemukan 3 genus FMA, yakni Glomus sp., Gigaspora sp. dan Acaulospora sp. Hasil ini sama seperti yang ditemukan pada areal pasca penambangan nikel di Soroako dimana hanya ketiga genus tersebut yang ditemukan di area tersebut ${ }^{(14)}$. Glomus ditemukan di sebagian besar lokasi penelitian, yang menunjukkan bahwa Glomus adalah genus FMA yang mendominasi di ketiga lokasi lahan pasca tambang timah tersebut. Genus Gigaspora hanya ditemukan di lokasi lahan pasca tambang Nibung pada rizosfir tumbuhan Pennisetum purpureum Schumach dan tumbuhan Eleusine indica, sedangkan genus Acaulospora ditemukan hanya di lokasi lahan pasca tambang Kayu Ara pada rizosfir tumbuhan Ischaemum aristatum L.

Dari tabel di atas dapat diketahui bahwa jumlah spora FMA sangat beragam dari 22 sampel yang dianalisis (range 0 - 82). Ada 10 sampel tanah yang tidak ditemukan spora (jumlah = 0), yaitu di rizosfir tumbuhan Melastoma malabathrichum, Cyperus polystachyus Rottb, Xyris complanata R. Br dari lokasi lahan pasca tambang Nibung, Scleria purpurascens Steud, Chromolaena odorata, Fuirena umbellata Rottb dan Scleria levis Rotz dari lokasi daerah Jongkong, serta Scirpus mucronatus $\mathrm{L}$ dan Cyperus polystachyus Rottb dari lokasi Kayu Ara. Sementara itu, yang terbanyak jumlah sporanya adalah dari lokasi Nibung di rizosfir akar Pennisetum purpureum Schumach (Gambar 6) yang berjumlah 82 spora dengan 2 jenis FMA, yakni Gigaspora dan Glomus. Kedua FMA Gigaspora dan Glomus juga ditemukan di rizosfir tumbuhan Eleusine indica dengan jumlah spora 57 dari lokasi lahan pasca tambang Nibung.

Genus yang ditemukan telah disebutkan diatas yaitu: Glomus, Acaulospora, dan Gigaspora. Ketiga genus tersebut telah teruji efektif dan mampu berkembang dengan baik pada areal revegetasi ${ }^{(15)}$. Glomus adalah genus mikoriza dari famili Glomaceae, yang memiliki keberagaman jenis tertinggi dari yang lain. Spora glomoid, diproduksi di atau dekat permukaan tanah, di sporocarps, biasanya dengan peridium sebagian atau lengkap atau sebagai spora tunggal atau dalam kelompok di dalam tanah atau substrat. Spora berbentuk globos sub-globos, ovoid ataupun obovoid dengan dinding spora terdiri dari lebih dari satu lapis, berwarna hyaline sampai kuning, merah kecoklatan, coklat, dan hitam, berukuran antara $20-400 \mu \mathrm{m}^{(15)}$. Dalam satu genus mikoriza terdapat banyak jenis atau spesies. Genus spora Glomus yang ditemukan di lahan pasca tambang tersebut dapat dilihat pada Gambar 3 di bawah ini.

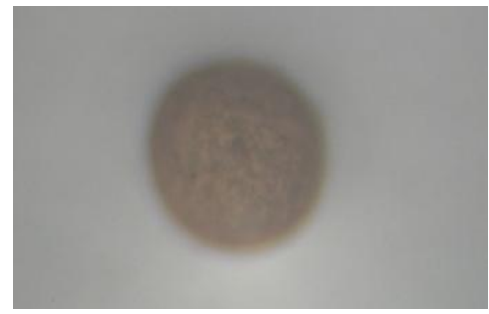

Gambar 3. Spora genus Glomus yang ditemukan dalam rizosfir tumbuhan di lahan pasca tambang timah, pada perbesaran 100x

Acaulospora adalah genus mikoriza yang termasuk dalam family Acaulosporaceae. Genus ini memiliki beberapa ciri khas antara lain yaitu memiliki 2-3 dinding spora, spora terbentuk di sisi samping leher Sporiferous Saccule, berbentuk globos hingga elips, berwarna hyaline, kuning, ataupun merah kekuningan, berukuran antara 100-400 $\mu \mathrm{m}^{(15)}$ ). Gambar 4 dibawah ini adalah salah satu genus Acaulospora yang telah teridentifikasi dalam sampel tanah dari area rizhosfir tumbuhan lahan pasca tambang timah.

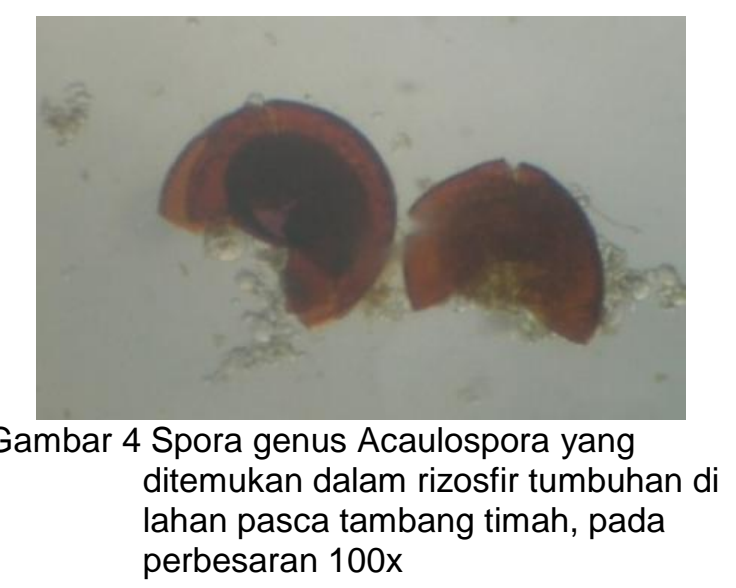

Gigaspora adalah genus mikoriza yang termasuk dalam family Gigasporaceae. Genus 
ini memiliki ciri khas, antara lain yaitu spora dihasilkan secara tunggal didalam tanah, tidak memiliki lapisan dinding spora dalam, terdapat Bulbous Suspensor, berbentuk globos atau subglobos, berwarna krem hingga kuning, berukuran 125-600 $\mu \mathrm{m}^{(15)}$. Gambar 5 dibawah ini adalah salah satu genus Gigaspora yang telah teridentifikasi ada dalam sampel tanah dari area rizhosfir tumbuhan lahan pasca tambang timah yang disampling.

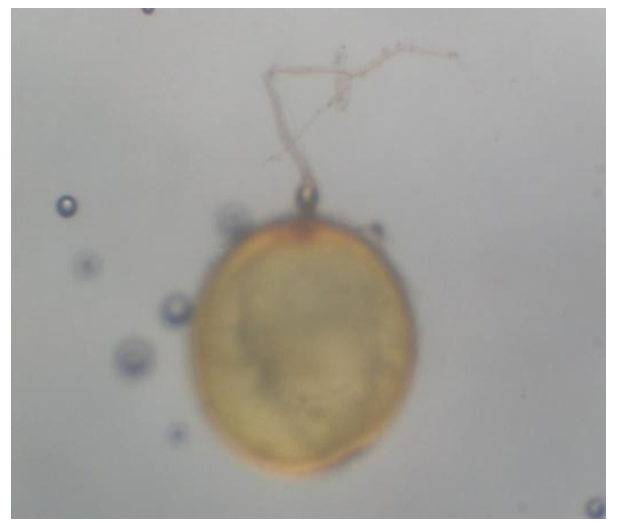

Gambar 5. Spora genus Gigaspora yang ditemukan dalam rizosfir tumbuhan di lahan pasca tambang timah, pada perbesaran $100 x$

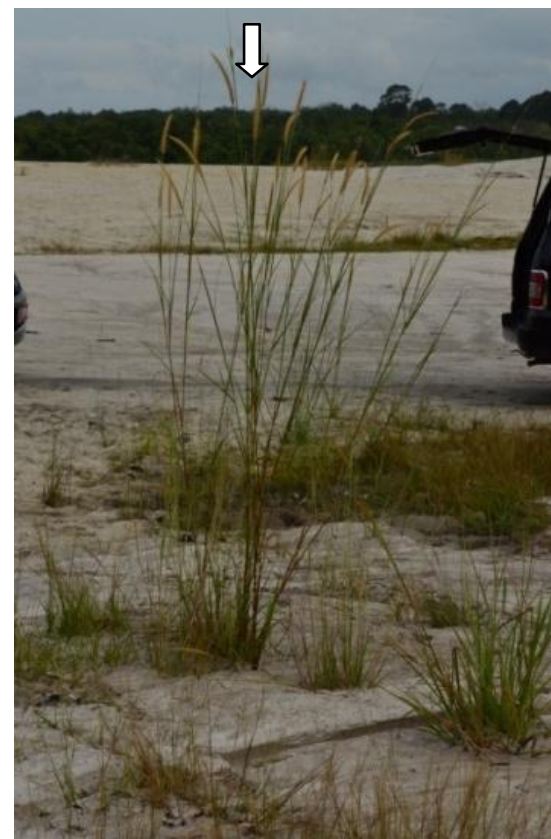

Gambar 6. Pennisetum purpureum Schumach yang tumbuh di lahan pasca tambang timah yang bersimbiosis dengan FMA genus Gigaspora dan Glomus, dengan kepadatan spora 82 per $50 \mathrm{~g}$ berat tanah
Terjadinya asosiasi antara fungi mikoriza arbuskula (FMA) dapat diketahui dengan ada tidaknya infeksi yang terjadi. Infeksi FMA dapat diketahui dengan adanya struktur-struktur yang dihasilkan oleh FMA antara lain, yaitu : hifa, miselia, vesikula, arbuskula, maupun spora. Hifa adalah salah satu struktur dari FMA berbentuk seperti benang-benang halus yang berfungsi sebagai penyerap unsur hara dari luar. Miselia merupakan kumpulan dari hifa. Arbuskula adalah unit kolonisasi yang telah mencapai sel korteks yang lebih dalam letaknya dan menembus dinding sel serta membentuk sistem percabangan hifa yang kompleks, tampak seperti pohon kecil yang mempunyai cabangcabang ${ }^{(15)}$.

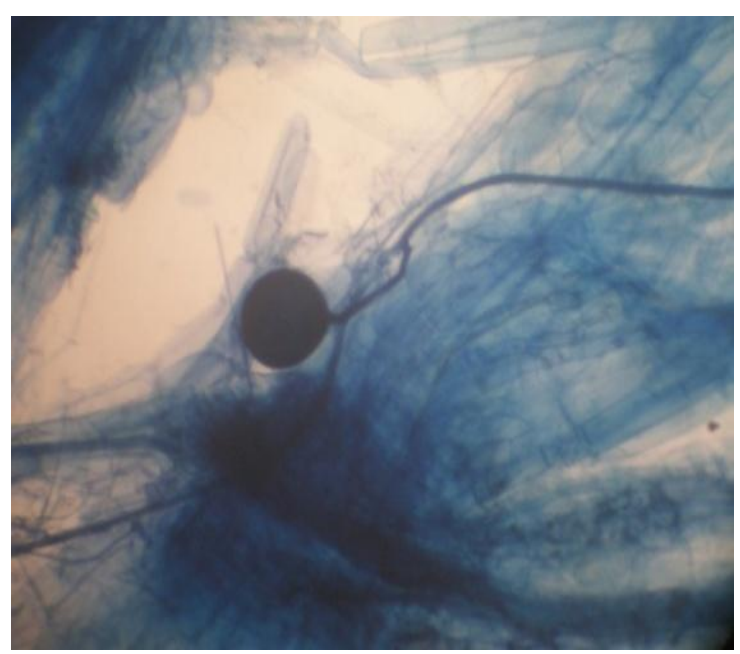

(a)

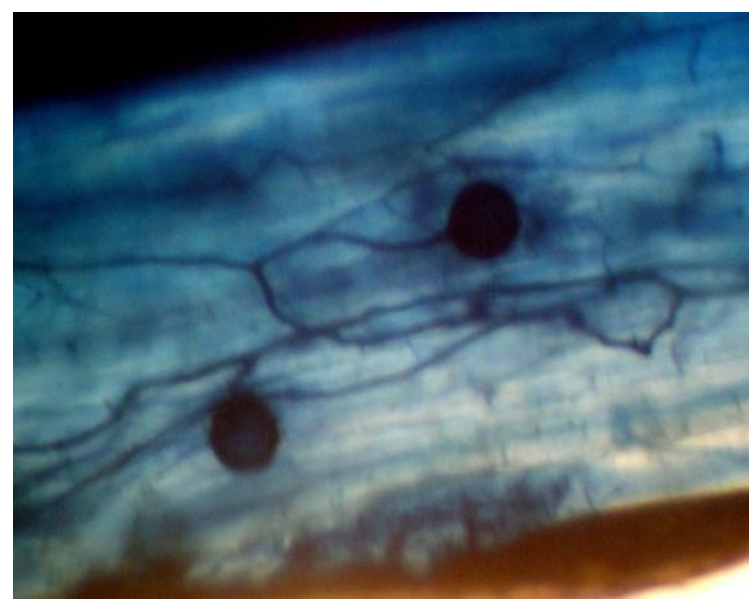

(b)

Gambar 7. Gambar a dan b adalah spora dan hifa FMA dalam akar tumbuhan yang hidup di lahan pasca tambang timah Kabupaten Bangka Tengah, pada perbesaran $40 x$ 
Tabel 4, 5 dan 6 menyatakan hasil pengukuran persen kolonisasi FMA dalam akar tumbuhan yang hidup di lahan pasca tambang timah, yang dihitung berdasarkan ada tidaknya struktur mikoriza dalam akar (infeksi akar) yang telah diwarnai dengan Trypan Blue. Gambar 7 menunjukkan kolonisasi mikoriza FMA yaitu spora dan hifa, yang terdapat dalam akar tanaman yang hidup di lahan pasca tambang timah tersebut.

Tabel 4. Persen kolonisasi FMA dalam akar pada berbagai jenis tumbuhan lahan pasca tambang timah di daerah Nibung

\begin{tabular}{lc}
\hline \multicolumn{1}{c}{ Jenis tanaman } & \% kolonisasi \\
\hline Fimbrystylis pauciflora R. Br. & 30 \\
Jucciaea linifolia Vahl & 13 \\
Pennisetum purpureum & 28 \\
Schumach & \\
Cynodon dactylon (L.) Pers. & 1 \\
Eragrotis atrovirens (Desf.) & 0 \\
Trin. Ex Steud & \\
Eleusine indica & 38 \\
Melastoma malabathrichum & 0 \\
Xyris complanata R. Br. & 15 \\
Cyperus polystachyus Rottb & 30 \\
\hline
\end{tabular}

Tabel 5. Persen kolonisasi FMA dalam akar pada berbagai jenis tumbuhan lahan pasca tambang timah di daerah Jongkong

\begin{tabular}{lc}
\hline \multicolumn{1}{c}{ Jenis tanaman } & \% kolonisasi \\
\hline $\begin{array}{l}\text { Cyperus polystachyus } \\
\text { Rottb }\end{array}$ & 40 \\
$\begin{array}{l}\text { Scleria purpurascens } \\
\text { Steud }\end{array}$ & 6 \\
$\begin{array}{l}\text { Gleichenia linearis } \\
\text { (Burm.) C.B.Clarke }\end{array}$ & 31 \\
Fimbristylis dichotoma & 11 \\
(L.) Vahl & \\
Axonopus compressus & 25 \\
$\begin{array}{l}\text { (Sw) P. Beauv } \\
\text { Sporobolus viriginicus (L.) }\end{array}$ & 27 \\
Kunth & \\
Chromolaena odorata & \\
Fuirena umbellata Rottb & 47 \\
Scleria levis Rotz & 19 \\
\hline
\end{tabular}

Dari Tabel 4, 5 dan 6 di atas dapat diketahui bahwa persen kolonisasi FMA sangat beragam yaitu antara range $0-52 \%$. Hal ini menunjukkan bahwa untuk setiap lokasi, ada perbedaan jumlah kolonisasi. Tidak ada kolonisasi yang ditemukan pada tanaman Eragrotis atrovirens (Desf.) Trin. Ex Steud dan tanaman Melastoma malabathrichum di lokasi Kolong Nibung. Persen kolonisasi terbesar $52 \%$ ditemukan di lokasi Kolong Kayu Ara, yakni pada tanaman Cyperus polystachyus Rottb. Persentase kolonisasi sangat beragam menunjukkan bahwa tiap-tiap tanaman memiliki persentase infeksi yang berbeda-beda. Beberapa penelitian diketahui bahwa simbiosis FMA dipengaruhi oleh level fosfat $(P)$, sumber $P, p H$, efektifitas isolat FMA dan kebergantungan tanaman inang terhadap mikoriza ${ }^{(12)}$.

Tabel 6. Persen kolonisasi FMA dalam akar pada berbagai jenis tumbuhan lahan pasca tambang timah di daerah Kayu Ara

\begin{tabular}{lc}
\hline \multicolumn{1}{c}{ Jenis tanaman } & \% kolonisasi \\
\hline Scirpus mucronatus $\mathrm{L}$. & 9 \\
Ischaemum aristatum $\mathrm{L}$. & 26 \\
Fuirena umbellata Rottb & 39 \\
Cyperus polystachyus & 52 \\
Rottb & \\
\hline
\end{tabular}

Simbiosis FMA dengan tanaman inang, maka FMA mendapatkan pasokan karbon dari tanaman. Sebagian karbon yang ditranslokasikan ke FMA kemudian akan dialirkan ke rizosfir ${ }^{(16)}$. Karbon tersebut kemudian dimanfaatkan oleh berbagai mikroba untuk menjalankan daur biogeokimia dalam tanah termasuk pembentukan dan pemeliharaan struktur tanah ${ }^{(17) .}$ Peningkatan agregasi tanah akan berdampak positif terhadap pergerakan udara dan air sehingga secara tidak langsung juga dapat menekan terjadinya erosi. Oleh karena itu, keberadaan simbiosis mikoriza dengan demikian akan mendatangkan manfaat bagi tanah dan lingkungan. Mikoriza meningkatkan pertumbuhan tanaman pada tingkat kesuburan tanah yang rendah, lahan terdegradasi, dan membantu memperluas fungsi sistem perakaran dalam memperoleh nutrisi ${ }^{(8)}$.

Mikoriza meningkatkan luas permukaan kontak dengan tanah, sehingga meningkatkan daerah penyerapan akar hingga 47 kali lipat, yang mempermudah melakukan akses terhadap unsur hara di dalam tanah. Mikoriza tidak hanya meningkatkan laju transfer nutrisi di akar tanaman inang, tetapi juga meningkatkan ketahanan terhadap cekaman biotik dan abiotik (15). Dengan demikian untuk meningkatkan keberhasilan program revegetasi lahan-lahan terdegradasi seperti lahan bekas tambang, FMA sangat diperlukan. Secara ekologis, FMA adalah pembenah tanah yang ramah lingkungan dan tidak menyebabkan pencemaran lingkungan seperti pupuk kimia.

Secara ekonomis, aplikasi FMA sangat efektif dan efisien, dimana FMA mampu mengefisiensikan penggunaan pupuk dengan hifa eksternalnya yang bisa mengirimkan hingga $80 \% \mathrm{P}, 25 \% \mathrm{~N}, 10 \% \mathrm{~K}, 25 \% \mathrm{Zn}$, dan $60 \%$ $\mathrm{Cu}^{(18)}$. Akar tanaman yang terinfeksi mikoriza 
terbukti mampu meningkatkan penyerapan air menjadi tiga kali lipat ${ }^{(19)}$. Selain itu FMA merupakan pembenah tanah yang hanya cukup sekali digunakan (once application), karena FMA merupakan makhluk hidup yang dapat terus tumbuh dan berkembang ${ }^{(15)}$.

\section{KESIMPULAN}

Hasil analisis Fungi Mikoriza Arbuskula (FMA) dari lahan pasca tambang timah Kabupaten Bangka Tengah yaitu Nibung, Kayu Ara dan Jongkong, ditemukan 3 genus FMA, yakni Glomus, Gigaspora, dan Acaulospora. Genus Glomus adalah genus FMA yang mendominasi di ketiga lokasi sampling tersebut. Jumlah spora paling banyak ditemukan pada rizosfir akar Pennisetum purpureum Schumach yang berjumlah 82 spora dengan 2 genus FMA, yakni Gigaspora dan Glomus. Persen kolonisasi FMA terbesar (52\%) ditemukan di lokasi lahan pasca tambang timah Kayu Ara, yakni pada tumbuhan Cyperus polystachyus Rottb.

\section{PERSANTUNAN}

Ucapan terimakasih disampaikan kepada Dr. Ir. Arie Herlambang, M.Si. selaku Kepala Balai Teknologi Lingkungan (BTL) BPPT, juga kepada Dr. Ir. Budhi Priyanto, MSc, Ir. Fadliah Salim, MSc.dan staf BTL lainya yang mendukung terselenggaranya penelitian ini sehingga penelitian ini dapat berjalan dengan lancar.

\section{DAFTAR PUSTAKA}

1. Inonu,I. (2013), Pengelolaan Lahan Tailing Timah di Pulau Bangka: Penelitian yang Telah Dilakukan dan Prospek ke Depan, Program Studi Agroteknologi-FPPB Universitas Bangka Belitung

2. Sujitno S., (2007), Sejarah Timah di Pulau Bangka. PT. Tambang Timah Tbk. Pangkalpinang.

3. Latifah, (2000), Keragaman Pertumbuhan Acacia mangium Wild pada Lahan Bekas Tambang Timah (Studi Kasus di Area Kerja PT. Tambang Timah). Tesis Magister IImu Kehutanan Program Pascasarjana IPB, Bogor (tidak dipublikasikan)

4. Nurdin, (2001), Kontribusi Mikoriza pada Proses Biogeokimia di Tanah Galian Tambang Emas dan Serapan Hara untuk Pertumbuhan semai Paraserianthes falcataria (L.) Nielson dan Acacia mangium Wild. Skripsi. Jurusan Managemen Hutan. Fakultas Kehutanan IPB Bogor.
5. Delvian, (2004), Aplikasi Cendawan Mikoriza Arbuskula dalam Reklamasi Lahan Kritis Pasca Tambang. Karya IImiah Jurusan Kehutanan, Fakultas Pertanian, Universitas Sumatera Utara, Medan. Hal 57.

6. Morte, A., C. Lovisolo, and A. Schubert, (2000), Effect of Drought Stress on Growth and Water Relations of the Mycorrhiza Association Helianthemum Almeriense Terfecia claveryi. Mycorrhiza 10; 115-119.

7. Marschner, H. (1995), Mineral Nutrition of Higher plants, $2^{\text {nd }}$ Edition, Academic Press Limited, London.

8. Suharno dan R.P. Sancayaningsih, (2013), Fungi Mikoriza Arbuskula: Potensi Teknologi Mikorizoremediasi Logam Berat dalam Rehabilitasi Lahan Tambang, Bioteknologi 10 (1): 31-42

9. Pacioni, G., (1992), Wet sieving and decanting techniques for the extraction of spores of VA mycorrhyzal fungi. Methods in Microbiology. Academic Press Inc. San Diego 24: 317-322.

10. Brundrett, M., N. Beegher, D. Dell, T. Groove, and N. Malajczuk, (1996), Working with Miycorrhizas in Forestry and Agriculture, ACIAR Monograph 32, Canberra.

11. Schenk N.C, and Y. Perez, (1990), Manual for Identification of VA Mycorrizhal Fungi. Florida. University of Florida.

12. Invam, (2010), Classification of Glomeromycota. http://invam.caf.wvu.edu/ diakses 12 Oktober 2015.

13. Phillips, J.M., and D.S. Hayman, (1970), Improved Procedures for Clearing Roots and Staining Parasitic and Vesicular Arbuskular Mycorrhizal Fungi for Rapid Assesment of Infection. Transact Brit. Mycol. Soc. 55 ; 158-161.

14. Giovannetti,M., and B. Mosse, (1980), An Evaluation of Techniques for Measuring Vesicular Arbuscular Mycorrhizal Infection in Roots. New Phytologist 84 (3); 489-500.

15. Setiadi Y. dan. A. Setiawan, (2011), Studi Status Fungi Mikoriza Arbuskula di Areal Rehabilitasi Pasca Penambangan Nikel (Studi Kasus PT INCO Tbk. Sorowako, Sulawesi Selatan), Jurnal Silvikultur Tropika, Vol. 03 No. 01, Hal. 88-95

16. Smith SE and D. Read, (2008), Mycorrhizal Symbiosis. Third Edition. Academic Press, Elsevier, New York. 
17. Rillig M.C., and D.L. Mummey, (2006), Mycorrhizas and soil structure. New Phytologist, 171; 41-53.

18. Marschner, H and B. Dell, (1994), Nutrient Uptake in Mycorrhizal Symbiosis. Plant Soil, 159:89-102.
19. Tuheteru, FD., Husna, A. Arif, I. Mansur, (2012), Pupuk Hayati Mikoriza untuk Budidaya dan Rehabilitasi Wilayah Pantai, Seameo Biotrop, Bogor, hal. 23. 